Ege Tıp Dergisi / Ege Journal of Medicine 2017;56(2):82-85

\title{
Bariatrik cerrahi ile ilgili ilk sonuçlarımız
}

\author{
Our initial results related to bariatric surgery \\ Turgut Anuk $^{1} \quad$ Neşet Köksal ${ }^{1} \quad$ Fatih Avşar $^{1} \quad$ Tülay Diken Allahverdi $^{1} \quad$ Barlas Sülü ${ }^{1}$ Hülya Çakmur ${ }^{2}$
${ }^{1}$ Kafkas Üniversitesi Tıp Fakültesi, Genel Cerrahi Anabilim Dalı, Kars, Türkiye
${ }^{2}$ Kafkas Üniversitesi Tıp Fakültesi, Aile hekimliği Anabilim Dalı, Kars, Türkiye
}

Öz

Amaç: Obezite ile mücadelede diyet egzersiz ve çeşitli medikal tedaviler denenmiş ancak başarı sağlanamaması üzerine etkin bir tedavi yöntemi geliştirmek üzere pek çok araştırma yapılmıştır. Bu retrospektif çalışmada, bariatrik cerrahi uygulana hastalardaki ilk sonuçlarımızı irdeledik.

Gereç ve Yöntem: Haziran 2012 - Haziran 2015 tarihleri arasında endokrinolojik ve psikolojik açıdan değerlendirilmiş, daha önceki tıbbi tedavi yöntemleri başarısız olmuş 20 morbid obez hasta çalışmaya alındı. Hastalar; yaş, cinsiyet, ek hastalıklar, ameliyat öncesi ve sonrası vücut kitle indeksleri (VKI), ameliyat komplikasyonları, ameliyat sonrası kilo kaybı miktarları ve önceden mevcut olan ek hastalıklar üzerine etkisi araştırıldı. Tüm veriler istatistiksel olarak analiz edildi, $p<0.05$ değerleri istatistiksel olarak anlamlı kabul edildi.

Bulgular: Hastaların ortalama yaşı 35.5 (19-54) olup kadın erkek oranı 4/1 idi. Ameliyat öncesi VKi ortalaması 48.4_ $5.2 \mathrm{~kg} / \mathrm{m} 2$ idi. Hastaların 17'sine primer 3'üne gastrik band sonrası yeniden kilo alma nedeni ile redo cerrahi uygulandı. On sekiz hastaya laparaskopik sleeve gastrektomi (LSG), 2 hastaya Roux-en-Y gastrik bypass (RYGB) yapıldı. Ameliyat sonrası 1 aylık dönemde bir hastada derin ven trombozu bir hastada yara yeri enfeksiyonu gözlendi. Redo RYGB uygulanan bir hasta postoperatif 6. ayda kaybedildi. Ortalama izlem süresi 18 (6-36) ay idi. Ameliyat sonrası VKI ortalaması $33.6 \pm 2.8 \mathrm{~kg} / \mathrm{m}^{2}$, ortalama kilo kaybı $42.2(20.2-66.3) \mathrm{kg}$ idi. VKi'lerinin ameliyat öncesi ve sonrası ortalama değerleri arasında istatistiksel olarak anlamlı fark gözlendi $(p<0.001)$. Preoperatif mevcut olan ek hastalıklarda ameliyattan sonra belirgin derecede düzelme görüldü.

Sonuç: Bariatrik cerrahi, doğru hasta seçimi ve deneyimli merkezlerde yapılması durumunda, obezite tedavisinde etkin ve güvenilir bir yöntemdir.

Anahtar Sözcükler: Bariatrik cerrahi, obezite, sleeve gastrektomi.

\section{Abstract}

Aim: Diet, exercise and various medical treatments had been tried in struggling with obesity, but since most of them did not reach a satisfactory success, many researches have been made in order to develop an effective method for the treatment. In this retrospective study, we report the initial outcomes of bariatric surgery in obese patients.

Materials and Methods: Between June 2012 and June 2015, 20 morbid obese patients whose previous treatment modalities failed were evaluated endocrinologically and psychologically and underwent bariatric surgery. Age and gender of the patients, comorbidities, body mass indices (BMI) before and after operation, complications, the amount of weight loss after surgical intervention and its effect on existing comorbidities were investigated. All data were analysed statistically and a value of $p<0.05$ was considered as statistically significant.

Results: The mean age of the patients was 35.5 (19-54) with a 4/1 female/male ratio. Preoperative BMI was $48.4 \pm 5.2 \mathrm{~kg} / \mathrm{m}^{2}$. Primary surgery was performed on 17 patients and redo surgery was performed on 3 patients after gastric band ligation because of regaining weight. Eighteen patients underwent laparascopic sleeve gastrectomy (LSG) and two patients underwent Roux-en-Y gastric bypass (RYGB). In the postoperative one-month period, deep venous thrombosis developed in one patient and wound infection in one patient. One patient who underwent redo RYGB died in the postoperative $6^{\text {th }}$ month. Mean follow-up period was 18 (6-36) months. Postoperative mean BMI and mean weight loss was $33.6 \pm 2.8 \mathrm{~kg} / \mathrm{m}^{2}$ and $42.2(20.2-66.3) \mathrm{kg}$ respectively. The difference between preoperative and postoperative mean BMI values was statistically significant $(p<0.001)$. After operation, marked improvement was noted in patients having associated diseases preoperatively.

Conclusion: Bariatric surgery is an efficient and reliable treatment method in obesity therapy with proper patient selection in experienced centers.

Keywords: Bariatric surgery, obesity, sleeve gastrectomy.

Yazışma Adresi: Turgut Anuk

Kafkas Üniversitesi Tıp Fakültesi, Genel Cerrahi Anabilim Dalı,

Kars, Türkiye

Makalenin Geliş Tarihi: 11.06.2016 Kabul Tarihi: 09.08.2016 


\section{Giriş}

Obezite, gelişmiş ve gelişmekte olan ülkelerde en önemli sağlık sorunları arasında ilk sıralarda yer almaktadır. Günümüzde obeziteye bağlı kronik hastalıklar (kanser, kardiyovasküler hastalık, tip 2 diyabet, vb.), fiziksel bozukluklar ve psikolojik problemler daha sık görülmektedir. Yaygınlaşan obezitenin tedavisi için yapılan harcamalar da her geçen gün artmaktadır.

Dünya Sağlık Örgütü'ne göre bugün yaklaşık 1.7 milyar erişkin aşırı kilolu (VKI $>25 \mathrm{~kg} / \mathrm{m}^{2}$ ) ve bunların yaklaşık \%30'u obezdir (VKI>30 kg/m²) (1). OECD verilerine göre ise yakın gelecekte her üç kişiden ikisi aşırı kilolu veya obez olacaktır. Her yıl yaklaşık 2.8 milyon kişinin obezite veya aşırı kilo sonucu öldüğü göz önüne alındığında durumun ne kadar tehlikeli olduğunu ortaya çıkmaktadır.

Bütün olumsuzluklarına rağmen obezitenin önlenebilir veya tedavi edilebilir olduğu savunulmaktadır. Bu amaçla diyet, egzersiz ve medikal tedavi gibi birçok tedavi protokolleri uygulanmaktadır. Ancak bu yöntemlerin uygulanmasından kısa süre sonra kaybedilen kiloların tekrar alındığı gözlenmiştir.

$\mathrm{Bu}$ yöntemlerde beklenen başarı sağlanamaması üzerine 20. Yüzyılın ortalarından itibaren bariatrik cerrahi yöntemleri alternatif bir tedavi olarak uygulanmaya başlanmıştır. Cerrahi yöntemler; kısıtlayıcı, emilim bozucu ve kombine işlemlerden oluşmaktadır. Kısa dönem sonuçlarına göre, kilo kaybının cerrahi dışı yöntemlere göre daha hızlı olması nedeniyle bu yöntemler günümüzde tüm dünyada artan sayıda kullanılmaktadır.

$\mathrm{Bu}$ çalışmada kliniğimizde laparoskopik sleeve gastrektomi (LSG) ve Roux-en-Y gastrik bypass (RYGB) bariatrik cerrahi uyguladığımız hastalardaki erken dönem sonuçlarımızı irdeledik.

\section{Gereç ve Yöntem}

Haziran 2012 - Haziran 2015 tarihleri arasında Kafkas Üniversitesi Tıp Fakültesi Araştırma ve Uygulama Merkezi Hastanesi Genel Cerrahi Anabilim Dalı'nda morbid obez tanısıyla opere edilen hastaların dosya kayıtları, etik kurul onayı alındıktan sonra retrospektif olarak tarandı. Obezitede cerrahi için çok sayıda kriterler olmasına rağmen biz çalışmamızda American Society of Bariatric Obesity-Surgery kriterlerini baz aldık (Tablo-1) (1). Tüm hastalar ameliyat öncesi kardiyoloji, psikiyatri, göğüs hastalıkları ve anestezi bölümleri ile konsülte edildi. Özofagus, mide ve duodenumu değerlendirmek için üst endoskopik inceleme uygulandı. Batın ultrasonografisi çekildi. Endokrinolog tarafından konsülte edilen ve hormonal hastalık tespit edilmeyen hastalar için operasyon kararı alındı. Ameliyat öncesi bilgilendirme yapılarak tüm hastalardan bilgilendirilmiş yazılı onam alındı.
Tablo-1. American Society of Bariatric Surgery-Obesity Kriterleri (1).

- Vücut kitle indeksinin $40 \mathrm{~kg} / \mathrm{m}^{2}$ nin üstünde olması veya 30-40 arasında olup eşlik eden hastalık bulunması (hipertansiyon, diyabet, uyku apne sendromu, diz eklemlerinde artritik dejenerasyon)

- 18-65 yaş arasında olmas

- Obezitenin en az 3 yıldır devam etmesi

- Hormonal hastalık bulunmamas

- Alkol ve ilaç bağımlısı olmaması

- Hastanın uygulanacak yöntemi anlaması ve ameliyattan sonra uyum sağlayabilecek durumda olması

- Ameliyat riskinin kabul edilebilir düzeyde olması

Ameliyat öncesi tüm hastalara $1 \times 0.6 \mathrm{IU}$, postoperatif ise 7 gün 2x0.6 ï̈ düşük molekül ağırlıklı heparin subkutan uygulandı. Ayrıca hastalar mobilize oluncaya kadar bilateral dizüstü varis çorabı giydirildi. Preoperatif amprik ve postoperatif geniş spektrumlu sefalosporin grubu antibiyotik verildi. Hastaların operasyon süreleri ortalama 2.2 saat (2.0-6.5) olup peroperatif komplikasyon görülmedi. Çıkarılan tüm piyesler değerlendirilmek üzere patolojiye gönderildi. Hastaların ortalama yatış süreleri 3.5 gün olup hiçbir hastamızda peroperatif mortalite görülmedi.

Operasyon öncesi VKi ve ağırlık değerleri kaydedildi. Operasyon sonrası hastalar hastanemiz bünyesinde Aile Hekimliği Anabilim Dalı tarafından kurulan obezite polikliniğine yönlendirildi ve beslenme eğitimi ve uygun diyet programı almaları sağlandı. Ayrıca hastaların operasyon sonrası 1. ay, 3. ay, 6. ay ağırlık, VKi değişimleri ve fazla kilo kaybı yüzde değerleri (\%FKK) kaydedildi.

Çalışmada, primer/redo cerrahinin hastalardaki etkisi, operasyon öncesi ve sonrası kilo kaybı ve VKI'deki değişiklikler ile ek hastalıklardaki durum karşılaştırılarak değerlendirildi (Tablo-2)

Tablo-2. Hastaların Demografik Özellikleri.

\begin{tabular}{l|c}
\hline Özellikler & Ortalama Değerler \\
\hline Yaş (yıl) & $31.5(19-54)$ \\
\hline Cinsiyet (K/E) & $4 / 1$ \\
\hline Primer cerrahi / Redo cerrahi & $17 / 3$ \\
\hline $\begin{array}{l}\text { Sleeve gastrektomi / Roux-N-Y } \\
\text { Gastrik bypass }\end{array}$ & 9 \\
\hline VKi $\left(\mathrm{kg} / \mathrm{m}^{2}\right)$ & $48.4 \pm 5.2$ \\
\hline
\end{tabular}

\section{Istatiksel Analiz}

Verilerin analizi SPSS for Windows 22 (Chicago, IL, USA) paket programında yapıldı. Sürekli değişkenlerin dağılımının normale yakın olup olmadığı KolmogorovSmirnov testiyle araştırıldı. Tanımlayıcı istatistikler sürekli değişkenler için ortalama standart sapma veya ortanca (minimum-maksimum) olarak kategorik değiş- 
kenler ise olgu sayısı ve (\%) şeklinde gösterildi. Gruplar arasında ortalamalar yönünden farkın önemliliği Student's $t$ testi ile ortanca değerler yönünden farkın önemliliği Mann Whitney $U$ testi ile incelendi. Kategorik değişkenler Pearson'un Ki-Kare testiyle değerlendirildi. $p<0.05$ değeri, istatistiksel olarak anlamlı kabul edildi.

\section{Bulgular}

Çalışmaya preoperatif incelemeleri tamamlanmış 20 hasta dahil edildi. Hastaların ortalama yaşı 35.5 (19-54) olup kadın/erkek oranı 4/1 idi. Ameliyat öncesi VKi ortalaması $48.4 \pm 5.2 \mathrm{~kg} / \mathrm{m}^{2}$ saptandı. Ek hastalık olarak 5 hastada hipertansiyon, 1 hastada infertilite ve 4 hastada da tip 2 diyabet mevcuttu. Hastaların 17'sine primer, 3'üne gastrik band sonrası yeniden kilo alma nedeni ile redo cerrahi uygulandı. On sekiz hastaya LSG, 2 hastaya RYGB yapıldı. Hastaların ortalama izlem süresi 18 ay (6-36) idi. Ameliyat sonrası 1 aylık dönemde 1 hastada derin ven trombozu, 1 hastada yara yeri enfeksiyonu gözlendi. Redo RYGB uygulanan 56 yaşındaki kadın hasta postoperatif 6 . ayda kaybedildi. Hastaların ameliyat sonrası VKI ortalaması $33.6 \pm 2.8$ $\mathrm{kg} / \mathrm{m}^{2}$, ortalama kilo kaybı değeri $42.2 \mathrm{~kg}$ (20.2-66.3), kilo kaybı oranı için ortalama değer 29.9 (16-44) idi. VKI'lerinin ameliyat öncesi ve sonrası ortalama değerleri arasında anlamlı fark gözlendi $(p<0.001)$. Preoperatif dönemde mevcut olan ek hastalıklarında gerileme gözlendi.

\section{Tartışma}

Obezite, tüm dünyada ve ülkemizde sıklıkla görülen temel sağlık sorunlarından biridir. Sosyo-ekonomik düzeyi yüksek toplumlarda teknolojinin ilerlemesi ile beraber fiziksel aktivite yetersizliği ve beslenme alışkanlıklarının değişmesi (dengesiz ya da aşırı beslenme) obezitenin en önemli çevresel nedenlerini oluşturmaktadır. Sosyo-ekonomik düzeyi düşük toplumlarda ise, özellikle uygun gıda bulma olanaklarının kısıtlı olması, kişilerin tek yönlü beslenmesine neden olarak obezite insidansında artışa yol açmaktadır. Erkek ve kadınlarda yaşın ilerlemesi ile birlikte obezite sıklığında artış görülmektedir. Yaş ilerledikçe bazal metabolizma hızı yavaşlamakta, enerji tüketimi azalmaktadır. Bu durumda enerji alımı azaltılmaz ise yaş ile beraber vücut ağırığı da artmaktadır $(3,4)$.

Obezite cerrahisinin ana hedefi obez hastalarda istenilen vücut ağırığını elde etmektir. Gelişen teknolojinin tıpta kullanımının artması ve devam eden araştırmalar, morbid obezite cerrahi tedavisinde yeni yöntemler ortaya çıkmasına katkı sağlamıştır. LSG günümüzde en sık uygulanan bariatrik cerrahi teknik olup mide hacminin azaltıldığı bir girişim olduğu için kısıtlayıcı bir işlemdir $(5,6)$. RYGB, hem gıda alımını kısıtlayıcı hem de absorpsiyon azaltıcı özelliği olan bir ameliyat şeklidir. LSG'nin teknik olarak RYGB'ye oranla çok daha rahat olması ve ayarlanabilir gastrik bant uygulanmasındaki yabancı cismin komplikasyonlarının olmaması gibi avantajlarının yanı sıra, sadece kilo kaybını sağlamayıp, metabolik iyileşmeye de katkı sağlaması daha fazla tercih edilen yöntem olmasını sağlamıştır (7).

Günümüzde ise bu yöntemler laparoskopik ve hatta robotik cerrahi ile yapılabilmektedir. Açık cerrahiye göre daha az ağrı, hasta konforunun yüksek olması, daha kısa sürede mobilizasyon, yara yeri enfeksiyonu ve insizyonel herni komplikasyonlarının az olması nedeniyle tercih edilmektedir (8). Bariatrik cerrahi, obezite için etkili bir tedavi ve istikrarlı uzun vadeli sonuçları ile etkili olduğu kanıtlanmıştır. Son yıllarda, LSG kilo kaybı, komorbidite ve postoperatif komplikasyonlar çözümlenmesi konusunda olumlu sonuçlar nedeniyle cerrahlar arasında genel kabul gören güvenilir bir bariatrik prosedürdür (9). LSG tekniğinin cerrahlar arasında popülaritesi her geçen gün artmakta ve teknik olarak uygulanabilirliği kolay olması nedeniyle gelecek vaat etmektedir. Cerrahın eğitim süresi kısadır ve daha kolay uygulanabilir bir prosedürdür. Fakat uzun dönem sonuçları henüz rapor edilmemiştir. Son yıllarda, hastaların memnuniyetin artması ile güvenilir bir hal almıştır (10). Çalışmamızdaki hastaların \%90'ına LSG tekniği başarı ile uygulanmıştır. LSG tekniği uyguladığımız hastalarımızdan birine daha önce laparoskopik ayarlanabilir gastrik banding uygulanmış olduğu ve bandın mide içine migrasyonu gözlendi. LSG'yi RYGB ile karşılaştırdığımızda; LSG'de üst gastrointestinal sistem endoskopisi yapılabilir. Oral alınan ilaçlarda absorbsiyon değişikliği olmaz, anastomoz yoktur, pilor korunduğundan dumping sendromu görülmez. LSG'de doğal gastrointestinal bütünlük korunur, malabsorbsiyon yoktur. Gereğinde diğer bariatrik cerrahi prosedürlere dönüştürülebilir.

LSG'nin en önemli ve korkulan komplikasyonu kaçak (\%2) olup sıklıkla his açısına yakın kısımda görülür. Son stapler hattının özofagusa yakın konulması, incisura angularis stenozu ve tübüler midenin bükülmesi kaçak nedenleri arasında sayılabilir. Bu komplikasyonu önlemeye yönelik birçok yöntem denenmiş ancak komplikasyon olasılığını ortadan kaldıracak bir teknik tanımlanamamıştır. Dikiş hattının ayrışması mekanik ve iskemik sebeplerden dolayı meydana gelir. Mekanik sebeplerden oluşan kaçaklar ilk 2 gün içinde oluşurken iskemi kaynaklar ayrışmalar inflamatuar ve fibrotik yanıtın en yoğun olduğu 5-7.günler arasında olur (11). Olgularımızda bu komplikasyona rastlanmadı.

Çalışmamızda, preoperatif dönemde mevcut olan ek hastalıklar arasında bulunan 5 hastadaki hipertansiyon, 1 hastadaki infertilite, 4 hastadaki diyabette ameliyat sonrası gerileme gözlendi. İnfertil olan obez hasta postoperatif 1 yılında hamileliği takiben sağlıklı bebek dünyaya getirdi. Regüle olmayan diyabeti olan obez hastalarda postoperatif dönemde kan glukoz regülasyonu sağlandı.

Ege Tıp Dergisi / Ege Journal of Medicine 
Daha önce Laparoskopik ayarlanabilir gastrik banding uygulan 56 yaşında bir kadın hastamızda izlem süresince yeterli kilo kaybı olmaması üzerine redo cerrahi olarak RYGB uygulandı ve şifa ile hastaneden çıkarıldı ancak postoperatif 6.ayda obeziteye bağlı nedenlerden kaybedildi.

\section{Sonuç}

Morbid obezite tanısıyla opere edilen hastalarımızın, ameliyat öncesi ve sonrası VKI'lerinin ortalama değerleri arasında anlamlı fark ve komorbiditelerde iyileşme açısından olumlu sonuçlar gözlendi. Daha anlamlı sonuçlar için uzun süreli takiplere ve daha çok sayıda hasta ile yapılan çalışmalara intiyaç vardır. Sonuç olarak, bariatrik cerrahi, doğru hasta seçimi ve tecrübeli merkezlerde yapılması halinde, sonuçları itibariyle günümüzde obezite ve metabolik cerrahi tedavisinde etkin ve güvenilir bir uygulamadır.

\section{Kaynaklar}

1. ASMBS Professional Resource Center. Available from: https://asmbs.org/resource-categories/guidelines-recommendations.

2. Deitel M. Overweight and obesity worldwide now estimated to involve 1.7 billion people. Obes Surg 2003;13(3):329-30.

3. Baysal A. Aksoy M, Bozkurt N ve ark. Diyet El Kitabı. Ankara: Hatiboğlu Yayınevi: 2011.

4. Kırım S. Obez hastalarda diyet, egzersiz ve ilaç tedavisinin homosistein düzeylerine etkisi. (Yandal Uzmanlık Tezi). Adana: Çukurova Üniversitesi; 2005

5. Lazzati A, Guy-Lachuer R, Delaunay V, et al. Bariatric surgery trends in France: 2005-2011. Surg Obes Relat Dis 2014;10(2):328-34

6. Reames BN, Finks JF, Bacal D, et al. Changes in bariatric surgery procedure use in Michigan, 2006-2013. JAMA 2014;312(9):959-61.

7. Rogula T, Khorgami Z, Bazan M, et al. Comparison of reinforcement techniques using suture on staple-line in sleeve gastrectomy. Obes Surg 2015;25(11):2219-24.

8. Atila K. Morbid obezitenin cerrahi tedavisi. Arc Clin Toxicol 2014;1(1):23-7.

9. Breathauer SA, Hammel JP, Schauer PR. Systematic reviw of sleeve gastrectomy as staging and primary bariatric procedure. Surg Obes Relat Dis 2009;5(4);469-75.

10. D'hondt M, Vanneste S, Pottel HN, Devriendt D, Van Rooy F, Vansteenkiste F. Laparoscopic sleeve gastretomy as a single stage procedure for the treatment of morbid obesity and the resulting quality of life, resolution of comorbidities, food tolerance, and 6- year weight loss. Surg Endosc 2011;25(8): 2498-504.

11. Baker RS, Foote J, Kemmeter P, et al. The science of stapling and leaks. Obes Surg 2004;14(10):1360-6 